\title{
Taking Nutritional Care of Elderly...!!
}

\section{Aradhana Dixit*}

Department of Food and Nutrition, India

*Corresponding Author: Aradhana Dixit, Department of Food and Nutrition, India.

Received: October 21, 2019; Published: November 05, 2019

DOI: 10.31080/ASNH.2019.03.0531

It is said old age never comes with calendar...but it is also true that a person's well being declines with time.

The person is less energetic, less movements, less physical work, so finally less motivated.

Similar effect is on her/his diet... Which may be summarized as follows?

Declined BMR: Basal Metabolic Rate declines. Body movement is less and exercise is also less.

Remedy: Give concentrated source of nutrients. This can be even in form of supplements.

Oral intake decreases: As jaws are impaired and teeth are weakened or lost a person cannot eat food.

Remedy: Give soft food ...which is chewable. Mostly boiled food with less oil and fats and stewed vegetables or soups works.

Development of bed sores: As person due to illness may continuously lie on bed...leads to bed sores and so discomfort.

Remedy: Give nutritionally balanced high protein diet as suggested by your dietitian.

Elderly anorexia: This can be due to stress, over thinking or insecurity feeling or due to disease...which results into decrease in appetite.

Remedy: Eat food slowly. Don't consume water in between the meals.

Diseases and medicines: Certain medicines decreases appetites...eat medicines as per recommendations...avoid eating empty stomach if suggested.

Remedy: don't eat medicines empty stomach mostly...too much antacids may create problems...instead cool milk and water lassi may give relief from acidity if persists.
Excess nutrient losses: when there is diarrhea or vomiting ...it may lead to nutrient losses...and depletion.

Remedy: eat food at temperature preferred. Food at extreme temperatures may be avoided.

Constipation or diarrhea : difficult stools due to indigestion or lack of exercise.

Remedy: eat soft fiber that may not irritate bowel. Drink Luke warm milk before sleep ...if no lactose intolerance.

Old age has its own nutritional challenges...but these can be overcome with the help of your healthcare professionals!!

where it is team work of doctor, nutritionists and nurse ...to develop healthy habits and well being.

\section{Volume 3 Issue 12 December 2019 \\ (C) All rights are reserved by Aradhana Dixit.}

